\title{
EFFECT OF ORGANIC MATTER ON DETERMINATION OF REACTIVE MERCURY IN CONTAMINATED WATERS
}

\author{
ELSA RAMALHOSA ${ }^{\mathrm{a}, *}$, SUSANA RIO SEGADE ${ }^{\mathrm{t}}$, EDUARDA PEREIRA ${ }^{\mathfrak{c}}$, \\ CARLOS VALE $^{\mathrm{d}}$ and ARMANDO DUARTE \\ ${ }^{a}$ Departamento de Agro-Indústrias, Escola Superior Agrária, Instituto Politécnico de \\ Branganca, 5300 Braganpa, Porrugal; 'Departamento de Quimica Analitica y Alimentaria, \\ Universidad de Vigo, Facultad de Ciencias de Durense, 32004 Ourense, Spain: \\ "Departamenta de Qüimica, Universidade de Aveiro, 3810-193 Aveiro, Portugal \\ Instituto de Investigacáo das Pescas e do Mar (IPIMAR), Av. Brasilia, \\ I400 Lisboa. Portugal
}

(Received 13 November 2001; In finat form 28 September 2002)

\begin{abstract}
Dissolved reactive mercury was determined in water samples from Ria da Aveito, a coastal lagoon contaminated by mercury. Conowntrations increased with acid dilution to a maximum of $193 \%$ in samples containing organic matter with high aromaticicy, as inferred from absorbancess at 250,280 and $365 \mathrm{~nm}$. Laboratory experiments with potassium hydrogenoftalate and humic acids solutions proved the influence of aromaticity in complexing mercury, bow acid dilution protonates the aromatic Hz-complexes and consequent release of labile forms of mercury to solution. On the basis of these results it is proposed that natural waters from mercury contaminated ecosystems should be analysed without dilutions, otherwise additional studies should be performed to access the protonation of mercury organic complexes.
\end{abstract}

Keywords: Reactive mercury; Organic matter; Flow injection; Cold vapour atomic fuorescence spectrometry: Natural waters

\section{INTRODUCTION}

The high toxicity of metcury and its derivatives requests reliable analytical data as a basis for the application of environmental quality regulations. Many studies have quantified metcury in natural waters in terms of total and reactive concentrations $[1,2]$. Total dissolved mercury includes organic and inorganic species while the reactive forms encompasses only the mercuric ion $\left(\mathrm{Hg}^{2+}\right)$ and its complexes, which are labile at ambient conditions (i.e., chloro- and hydtoxo-complexes, weak organic complexes, electrostatically adsorbed species, etc.) $[1,3]$.

*Corresponding author. Fax: +351-273-325405. E-mail: elsa@ipb.pt

ISSN 0306-7319 print: ISSN 1029-0397 online 2003 Taylor \& Francis Ltd DOI: $10.1080 / 0306731021000053757$ 
Cold vapour atomic absorption spectrometry (CV-AAS) and cold vapour atomic fluorescence spectrometry (CV-AFS) are the most widely used techniques for the mercury determination. The determination of total mercury present in natural waters requires the conversion of organomercury species into inorganic mercury using an oxidation step prior to the reduction to elemental mercury. Several combinations can be used, such as: oxidation with $\mathrm{BrCl}$ followed by reduction with $\mathrm{SnCl}_{2}$ [2] and gold preconcentration $[1,4,5]$ : oxidation with ultra violet (UV) irradiation (0.5 or $6 \mathrm{~h}$ ) foljowed by reduction with $\mathrm{SnCl}_{2}$ with or without gold preconcentration [4]; oxidation with $\mathrm{KMnO}_{4}$ followed by reduction with $\mathrm{NaBH}_{4}$ and gold preconcentration [4] or oxidation with potassium persulfate/UV irradiation ( 20 min) followed by reduction with $\mathrm{SnCl}_{2}[6,7]$. Reactive mercury is usually determined in acidified water samples with $\mathrm{HCl}[1,2,8]$ or $\mathrm{HNO}_{3}[3]$ to $\mathrm{pH}<2$ by $\mathrm{SnCl}_{2}$ reduction. Reactive mercury, also called 'easily reducible', 'acid labile' or 'ionic', is a very important substrate to reactions that form other $\mathrm{Hg}$ species such as methylmercury [1], known by its extreme toxicity and biomagnification in aquatic foodweb $[1,8]$.

It is well documented that some parameters such as water sample acidification can modify the reactive mercury concentration in relation to natural water samples. Bloom [1] observed that acidification to $\mathrm{pH} 2$ resulted in reactive mercury concentrations, which were immediately and temporarily higher than those observed in unacidified samples. However, as the sample was stored at low $\mathrm{pH}$, the fraction of reactive mercury decreased with time. Furthermore, the observed reactive mercury vs time varied amongst different water types. Millward and Bihan [9] observed that acidification of freshwater solutions to $\mathrm{pH} I$ released an additional $10 \%$ of detectable mercury, whilst seawater solutions acidified to $\mathrm{pH} 1$ gave a complete release of mercury. The higher reactive mercury quantities detected in the seawater samples were explained in terms of cation competition from $\mathrm{Ca}^{2+}$ and $\mathrm{Mg}^{2+}$ for sites in the humic material. These authors also referred that the complexes are only partially labile in freshwaters whilst complete decomplexation is observed in seawater. Indeed, it is well documented that mercury is both freshwater and seawater is dominated by complexation with natura] organic matter $[9,30]$.

This work examines how concentration of reactive mercury in contaminated waters varied with the acid dilution due to protonation of $\mathrm{Hg}$-complexes and consequent release of labile forms of mercury to solution.

\section{EXPERIMENTAL}

\section{Sampling and Pre-treatment of Water Samples}

Four water samples were collected in Ria de Aveiro, a coastal lagoon permanently connected to the sea at NW coast of Portugal and contaminated by an industrial effluent rich in mercury [11]. Water was filtered through $0.45 \mu \mathrm{m}$ Millipore filters (Millipore, Bedford, USA) and the filtrates were acidified to $\mathrm{pH}$ less than 2 with concentrated nitric acid (mercury free) for posterior reactive mercury determinations. An aliquot of the samples was filtered through glass fiber filters (Gelman, Ann Arbor, USA) to evaluate the nature of the dissolved organic matter. Heating at $450^{\circ} \mathrm{C}$ during $24 \mathrm{~h}$ cleaned the glass fiber filters. 


\section{Instrumentation and Measurements}

The reactive mercury was detcrmincd using a flow-injection-cold vapor-atomic fluorescence spectrometer (Hydride/vapor generator PS Analytical Model 10.003, coupled to a PS Analytical Model 10.023 Merlin atomic fluroscence spectrometer) (PS Analytical, Orpington, Kent, England) (FI-CV-AFS). This system is based on the injection flow tectnique, where the sample, water and reducing agent were injected separately through Tygon tubes by a peristaltic pump. The water and sample solutions flow-rates were $7.3 \mathrm{~cm}^{3} \mathrm{~min}^{-1}$ and the teducing agent flow-tate was $2.7 \mathrm{~cm}^{3} \mathrm{~min}^{-1}$. Elemental mercury was generated in a reaction coil. Mercury vapor in the quartz gas-liquid separator (PS Analytical) was purged ftom the solution with an argon stream $\left(300 \mathrm{~cm}^{3} \min ^{-1}\right.$ ) and swept into a drying tube, which consisted on a bygroscopic tubular membrane (Permapure, PS Analytical). Finally, mercury vapor was transferred to the quartz cell of the atomic fluoresecnce spectrometer (PS Analytical). Peak height measurements were performed using the software ' $\Lambda$ valon' (PS Analytical) of the fluorescence detector.

The nulure and the quantity of the organic matter present in the water samples were estimated by the method pioposed by Peauravuori and Pihlaja [12]. These atthors stated that spectroscopic properties may be applied, as a first approximation, for estimating the siee of humic solutes and their aromaticity in natural surface waters. The wavelength of $280 \mathrm{~nm}$ was chosen because $\pi \rightarrow \pi^{*}$ electron transition occurs in this UV region (ca. $270-280 \mathrm{~nm}$ ) for phenolic arenes, benzoic acids, aniline derivatives, polyenes and polycyclic aromatic hydrocarbons with two or more rings. Many of these compounds are thought to be common structural subunits in humic matter, particularly in that derived from terrestrial sources [12]. These authors also found a good inverse correlation between the quotient of the absorbances at 250 and $365 \mathrm{~nm}$ and the molecular size and aromaticity of aquatic humic solutes. The quantity and the nature of the organic nnatter present in water samples was thus estimated by the absorbances at 250,280 and $365 \mathrm{~nm}$ of the filtrates, oblained frum the glass fiber filters, measured in 1-cm quartz cells of an UV-spectrophotometer (UV-Vis Scanning Spectrophotometer UV-2101 PC, Shimadzu). The baseline was obtained with uItrapure water.

The carbon quantity present in the humic acids used in this work was determined by Elemental analysis (LECO model CHNS-932, St. Joseph, USA).

\section{Reagents}

Alt reagents were prepared in ultra-pure water produced in a Milli-Q Plus, Model 185 from Millipore. The chemicals were of analytical-reagent grade as well as mercury-free and used without further purification. The reducing agent, $2 \% \mathrm{~m} / \mathrm{v} \mathrm{SnCl}$ in $10 \% \mathrm{v} / \mathrm{v}$ hydrochloric acid, was prepared daily by the dissolution of the appropriate amount of mercury-free $\mathrm{SnCl}_{2}$ (Merck, p.a., Darmstadt, Germany) in mercury-firee hydrochloric acid (Merck) on a hot-plate. The solution was brought to volume with ultra-pure water. $\Lambda$ stock solution of mercury nitrate $\left(1000 \mathrm{mig}^{-3}\right.$, Spectrosol, BDH, Poole, England) was used weekly to prepare a working stindard solution of $10 \mathrm{mg} \mathrm{dm}^{-3}$ (as $\mathrm{Hg}$ ) in $2 \% \mathrm{v} / \mathrm{v}$ mercury-free nitric acid (Merck). The lower working standard solutions were prepared daily in $2 \% \mathrm{v} / \mathrm{v}$ nitric acid. Potassium hydrogenoftalate was 
purchased from Merck (Merck, p.a., Darmstadt, Germany) and the humic acids were purchased from Fluka (Fluka, Sigma Aldrich, Deifenhofen, Gemany).

\section{Figures of Merit}

The analytical performance of the FI-CV-AFS tochnique was evaluated using inorganic mercury standatds. The detection limit for inorganic merrọry varied from 1.1 to $8.9 \mathrm{pmol} \mathrm{dm}^{-3}$ and it was calculated from 44 calibration curves in the range of 10-100 pmol $\mathrm{dm}^{-3}$ and based on the amount necessary to yield a net signal equal to three times the standard deviation of the blank |131. Other calibration curves embracing other range of concentrations were also obtained when necessary. The relative standard deviation $(n=5)$ for a 100 pmol $\mathrm{dm}^{-3}$ inorganic nercury standard was less than $5 \%$. No peak was detected when the blank was analyzed.

\section{RESULTS ANO DISCUSSION}

\section{Incertitude in Deterwining Reactive Mercury}

Reactive mercury was delermined in the four water samples collected in Ria de Aveiro under undiluted conditions and after several acid dilutions with $2 \% \mathrm{v} / \mathrm{v}$ mercury-free nitric acid (Fig. 1). Concentrations in the Samples 1, 2 and 3 increased with the degree of dilution (43-54\% for Sample 1, 28-46\% for Sample 2 and $90-193 \%$ for Sample 3), and the final results differed significantly from the initial values (One-way ANOVA, $\alpha=0.05$ ). For Sample 4, the concentrations of diluted samples $(n=3)$ were not significantly different from initial samples. The increase in mercury concentiation as samples are diluted with the acid solution indicates that considerable amounts of mercury become more labile. However, mercury speciation responded differently to acid dilution in the four samples.

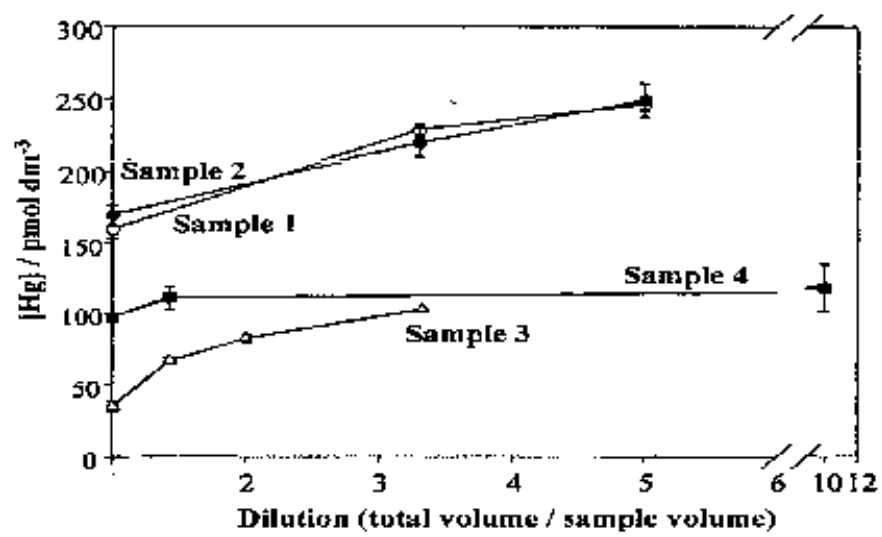

FIGURE 1 Reactive mercury concentrations (pmol $\mathrm{dm}^{-3}$ ) in four natural waters after dilutions with nitriv acid (Sample 1 (O); Sample 2(O); Sumple $3(\Delta)$ and Sample $4(a)$. 
TABLE I Absorbances at $280 \mathrm{~nm}$ (mean \pm standard deviation, $\mathrm{n}=6$ ) and ratio of the absorbances at 250 and $365 \mathrm{~nm}$ for the natural samples collected in Ria de Aveiro

\begin{tabular}{lcc}
\hline Sample & $A b s_{280 \mathrm{~nm}}$ & $A b s_{250 \mathrm{~nm}} / A b s_{365 \mathrm{~nm}}$ \\
\cline { 2 - 3 } 1 & $0.124 \pm 1.60 \times 10^{-3}$ & 4.2 \\
2 & $0.121 \pm 1.17 \times 10^{-3}$ & 4.2 \\
3 & $0.109 \pm 4.50 \times 10^{-4}$ & 5.5 \\
4 & $0.093 \pm 5.50 \times 10^{-4}$ & 20.0 \\
\hline
\end{tabular}

\section{Aromaticity of Dissolved Organic Matter}

To characterize the dissolved organic matter of the samples, the absorbance at 250,280 and $365 \mathrm{~nm}$ were measured (Table I). Samples 1,2 and 3 had slight higher absorbances at $280 \mathrm{~nm}$ than Sample 4, and the ratio of absorbances at 250 and $365 \mathrm{~nm}$ of Sample 4 was 4-5 times higher than the values obtained for the other samples. The organic matter present in Samples 1,2 and 3 showed thus much more aromaticity than the one present in Sample 4. This means that lower effect of acid dilution on mercury determination was registered in the sample containing organic matter with lower aromaticity.

\section{Experimental Work 1: Effect of Aromaticity in Mercury Lability}

In order to examine the behavior of mercury in the presence of organic matter with different aromaticity, potassium hydrogenoftalate $\left(488 \mu \mathrm{mol}\right.$ of $\left.\mathrm{C} \mathrm{dm}^{-3}\right)$ and humic acids $\left(473 \mu \mathrm{mol}\right.$ of $\left.\mathrm{C} \mathrm{dm}^{-3}\right)$ solutions were prepared. To prepare the humic acids solution, they were weighed and dissolved in an alkaline solution. After neutralization, several volumes of humic acids solution were transferred to $100 \mathrm{~cm}^{3}$ volumetric flasks in order to obtain concentrations of carbon between 0 and $333 \mu \mathrm{mol} \mathrm{dm}^{-3}$. A fixed quantity of mercury and $50 \mu \mathrm{L}$ of concentrated nitric acid (mercury free) were added. A similar procedure was followed with the potassium hydrogenoftalate. The mixtures were homogenized and analysed for mercury by FI-CV-AFS. The absorbance at 250, 280 and $365 \mathrm{~nm}$ were measured in the solutions prepared with potassium hydrogenoftalate and humic acids (Fig. 2). The absorbances at $280 \mathrm{~nm}$ varied linearly with the carbon concentration: $y=1.6 \times 10^{-4} x-5.0 \times 10^{-4}, r^{2}=1.00$ for potassium hydrogenoftalate and $y=6.2 \times 10^{-4} x+5.5 \times 10^{-4}, r^{2}=1.00$ for humic acids. Higher slope for humic acids reflects the presence of several compounds that absorb in this wavelength [14]. The absorbances at $365 \mathrm{~nm}$ of the potassium hydrogenoftalate solutions were very low and the ratio of absorbances at 250 and $365 \mathrm{~nm}$ was high implying a reduced aromaticity. Otherwise the ratio obtained for humic acid solutions was only 2.52 (with a range of 1.10), which indicates the high aromaticity of these solutions. Reactive mercury was determined in humic acid and potassium hydrogenoftalate solutions with different carbon concentration, after a fixed quantity of mercury and nitric acid have been added (Fig. 3). The percentages of mercury recovered in potassium hydgrogenoftalate solutions were adequately high $(86-94 \%)$, in comparison to humic acids solutions that showed a marked decrease of mercury recovery as carbon values increased (34-82\%). The contrasting recovery of mercury (in reactive forms) in the two solutions evidences the importance of the aromaticity of humic acids rather than the carbon concentration in complexing mercury. 


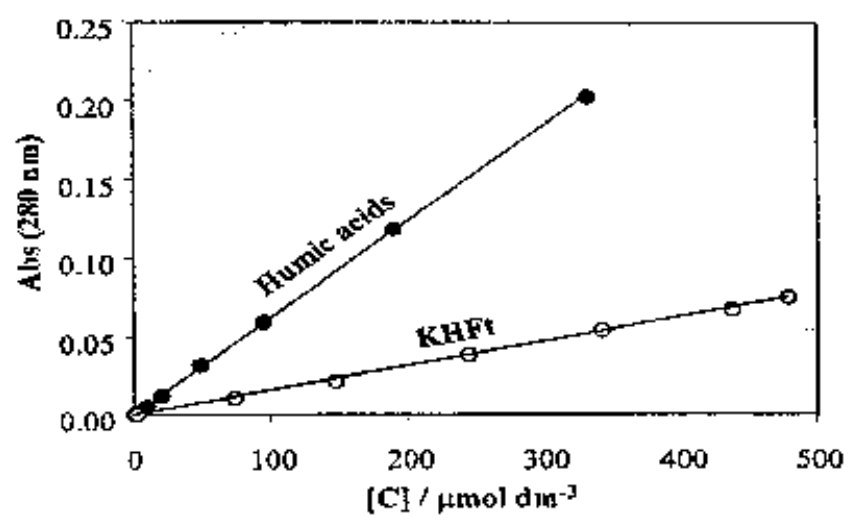

FIGURE 2 Absorbances at $280 \mathrm{~nm}$ for potassium hydrogenoftalate (O) and humic acids (\$) solutions.

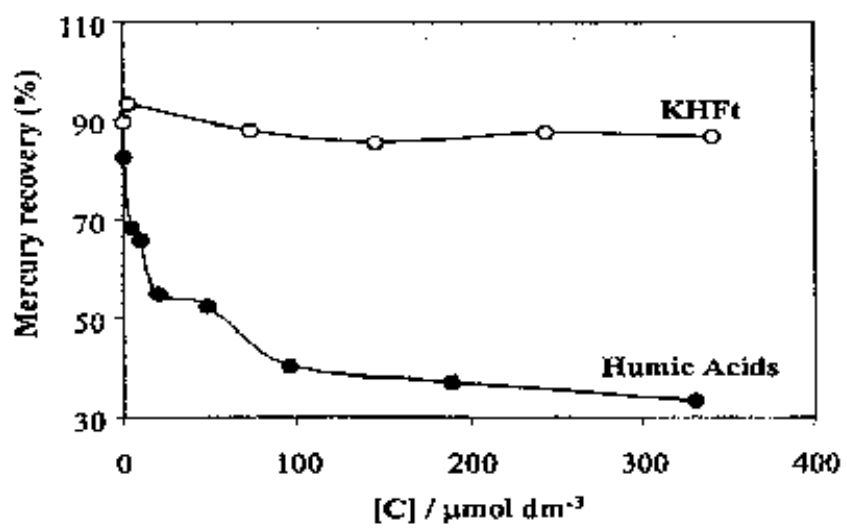

FIGURE 3 Mercury recovery $(\%)$ for several solutions of potassium hydrogenoftalate $(0)$ and humic acids (-) expressed as carbon concentration ( $\mu \mathrm{mol} \mathrm{dm}^{-3}$ ) with a fixed quantity of inorganic mercury.

\section{Experimental Work 2: Effect of Acid Difution on Mercury Complexation}

As a rule, the addition of acid to an aqueous solution causes the protonation of organic matter and subsequent release of inorganic mercury. In a first approach, the degree of this release is determined by the stability of mercury complexes. In order to investigate the stability of mercury-humic actds the following experience was performed. Inorganic mercury was added to a solution of humic acids with $480 \mu \mathrm{mol}$ of $\mathrm{C} \mathrm{dm}^{-3}$ and the volume was completed with ultra-pure water in order to obtain $498 \mathrm{pmol} \mathrm{dm}$ of inorganic mercury. The solution was allowed to equilibrate until obtaining similat mercury concentrations after two consecutive measurements at different times. The equilibration time was about $130 \mathrm{~min}$, which is comparable to the $90 \mathrm{~min}$ used for natural waters with $1 \mu \mathrm{g} \mathrm{dm}{ }^{-3}$ of mercury by Millward and Bihan [9]. After the equilibration period, the solution was acidified in a similar way to the natural water samples. Different volumes of this solution were transferred into volumetric flasks and dilute to volume with nitric acid $2 \% \mathrm{v} / \mathrm{v}$. Concentration of reactive mercury in the lowest dilution $\left(390 \mu \mathrm{mol} \mathrm{dm}^{-3}\right.$ of C) was $85 \mathrm{pmol} \mathrm{dm}^{-3}$, which correspond to $17 \%$ of the 


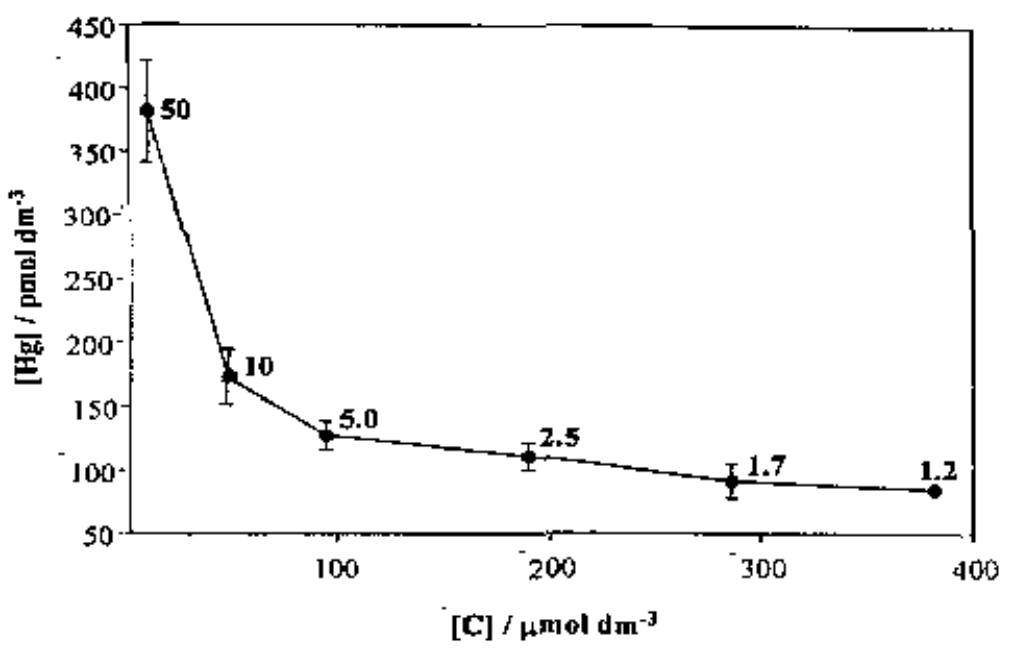

FIGURE 4 Mercury concentrations (pmol $\mathrm{dm}^{-3}$ ) determined in diluted solutions containing izitially $498 \mathrm{pmol} \mathrm{dm}^{-3}$ of mercury and $480 \mu \mathrm{mol} \mathrm{dm} \mathrm{m}^{-3}$ of humic acids (as carbon). The numbers above the symbols represent the dilution.

initial mercury (Fig. 4). The reactive mercury concentration increased with the dilution and reached $77 \%$ when the solution was diluted 50 times and $\mathrm{C}$ was $9.57 \mu \mathrm{mol} \mathrm{dm}{ }^{-3}$. This indicates that in spite of the high affinity of mercury to humic acids, some active sites are protonated in presence of acid and mercury is released to the solution. Such analytical behavior was similar to the one observed with contaminated estuarine waters from Ria de Aveiro.

\section{CONCLUSIONS}

On the basis of these results, it is recommended that reactive mercury determinations should be performed in undiluted samples. Dilution of contaminated waters containing organic matter with high aromaticity, resulted in the increase of labile mercury probably due to protonation of the aromatic organic matter. The consequence is an overestimation of reactive mercury in the real samples.

\section{Acknowledgements}

Two research grants are gratefully acknowledged: a PhD grant (PRAXIS/BD/11153/ 97) for E. C. D. Ramalhosa and a Pos-doc grant from Xunta de Galicia for S. Río Segade.

\section{References}

[1] N.S. Bloom, In: Watras, Carl J. and Huckabee, John W. (Eds.), Mercury Pollution: Integration and Synthesis. pp. S41-552. Lewis Publishers, California, USA (1994).

[2] M. Leermakers, C. Meuleman and W. Baeyens, Water. Atr und Soil Pollution, 80, 64|-652 (1995).

[3] J.A. Dalziel, Mfarine Chemistry, 49, 307-314 (1995). 
[4] K.J.M. Kramer, Ph. Quevauviller, W.S. Dorten, E.M. van der Vlies and H.P.M. Haan, Analyst, 123, 959-963 (1998).

[5] S. Coveli, J. Faganeli, M. Horvat and A. Brambeti, Estuarine, Coostal and Shelf Sctence, 48, 415-428 (1999).

[6] S. Montgomery, A. Mucci, M. Lucotte and P. Pichet, Can. J. Fish, Aquat. Sci., 52, 2483-2492 (1995).

[7] A. Mucci, M. Lucotte, S. Montgomery, Y. Plourde, P. Pichet and H.V. Tra, Con. J. Fish. Aquat. Sci., 52, $2507-2517$ (1995).

[8] W. Baeyens, Trends in Analytical Chemistry, 11(7), 245-254 (1992),

[9] G.E. Millward and A. Bihan, Water Research, L2, 979-984 (1978).

[10] Q. Wu, S.C. Apte, G.E. Batley and K.C. Bow]es, Aralytica Chimica Acta, 350, 129-134 (1997),

[1] M.E. Pereira, A.C. Duarte, G.E. Millward, C. Vale and S.N. Abrew, Sct. Tot, Environ., 213, 157-163 (1998).

[12] J. Peuravtori and K. Pihtaja, Analytica Chimica Acta, 337, I33-149 (1997).

[13] J.C. Miller and J.N. Miller, In: Elis Horwood Limited (Eds.), Statistics for Amalytical Chemistry, pp. 96-100. Jobn Wiley and Sons, West Sussex, England (1984).

[14] F.J. Stevenson, ln; Aiken, George R., McKnight, Diane M., Wersbaw, Robert L. and Maccartby, Patrick (Eds.), Soil, Sediment, and Water - Geochemistry, Ssolation, and Characterization, John Wikey and Sons, New York (1985). 
This document was created with Win2PDF available at http://www.daneprairie.com. The unregistered version of Win2PDF is for evaluation or non-commercial use only. 